\title{
WILDLIFE OFFENCES BY COMMUNITIES IN EASTERN RAJASTHAN
}

\author{
R.G. Soni ${ }^{1}$ and Satish Kumar Sharma ${ }^{2}$ \\ ${ }^{1}$ Additional Principal Chief Conservator of Forests and Chief \\ Conservator of Forests (Wildlife), Van Bhawan, Vaniki Path, Jaipur, \\ Rajasthan, India. \\ ${ }^{2}$ Range Forest Officer, Nahargarh Biological Park, 2 Suresh Nagar, \\ Durgapura, Jaipur, Rajasthan 302018, India
}

Shikar was banned by the Government of Rajasthan by enforcing the Wildlife (Protection) Act in 1972. This has not changed the habits of certain people living in and around the protected areas since illegal poaching and other similar acts sometimes take place. To control wildlife offences, the wildlife wing of the Forest Department, Rajasthan, has nine Wildlife Flying Squads which are stationed at different places all over the state. One of the flying squads has been stationed at Jaipur for the east-central part of the State. The Flying Squad (eastern zone) is working since 1974-1975. Initially its jurisdiction was wider (the entire state) but since 1984-1985 onward its patrolling is confined to districts of Jaipur, Dausa, Sikar and Jhunjhunu only. During the last 24 years (1974-1975 to 1997-1998), the Jaipur Flying Squad has recorded wildlife offences with as many as 383 cases registered.

Whenever a wildlife offence is detected, a departmental F.I.R. (First Information Report) is lodged by the Forest Officer either in office or in the field, whatever the case may be and then investigation is started. A record of all the F.I.R.s. is maintained in an Offence Register at the Range Office and in the division office as well. The data presented in this paper is taken from the records of the Range Office.

Scrutiny of data of 24 years reveal that offenders from more than four dozen castes, sub-castes, communities, tribes etc. were found involved in wildlife offences. Caste-wise offence data is

listed in Table 1. Gender issue is also an important factor in wildlife offences. This aspect was also studied. Relevant data is given in Table 2. Wild mammals, birds, reptiles, amphibians, fishes and other lifeforms in Rajasthan are susceptible to poaching. Table 3 lists species in trade and the nature of offence in the last 24 years.

As many as 24 mammal species, 13 bird species and 8 reptile species have been listed in Table 3. Bavarias are the top most wildlife offenders in the state.

People of Rajasthan are known for their dedication for conserving the wild animals and plants. Bishnoi communities are well known for the sacrifices they have made to protect the local fauna and flora since their Guru Jammeshwarji Maharaj launched this sect in $1542 \mathrm{AD}$. On the one hand there are staunch protectors like Bishnois but on the other hand some people are indifferent and yet some others indulge in hunting and poaching. Most tribals in Rajasthan are poor. They earn their livelihood from forests, forest produce and poaching. The land available with them being marginal and devoid of good irrigation facilities, keeps them in eternal poverty. They do not have any marketable surplus. Their agriculture production is totally dependent on monsoon rains. Since human population is rapidly increasing, their land holding is also proportionally decreasing (Doshi \& Vyas, 1992). Many tribals and other communities are largely illiterate and nonvegetarian. They are poor, follow primitive religions (animism), love drink and shikar. Few communities like Banjara, Nuts etc. are primarily nomads who wander from place to place. They like shikar. Nuts eat all type of flesh except of jackal (Singh \& Pandey, 1998).

It is a matter of dispute whether Bavariya (Bawria) or Bagri represent a single group or they are different nomadic communities. Some of them are also criminal by nature. They have well organised system of crimes and shikar operations. Table 1 reveals that they are at the top of the list of wildlife destroyers.

Madaris exhibit monkeys and bears in villages. Similarly Kalbalia (snake charmers) exhibit snakes and sometimes mongoose for their livelihood (Deoras, 1981). The main killers of cats are the nomadic Kalbalias and Jogies. Through generations of professional hunting they have mastered the techniques of shikar (Sankhala \& Sharma, 1984). Skin and fur

Table 2. Gender issue of wildlife offences

\begin{tabular}{lllllll}
\hline Period & Total cases & \multicolumn{2}{l}{ No. of cases where offender was } & \multicolumn{3}{l}{ No. of offenders involved in detected cases } \\
& registered & Detected & Not detected & Male & Female & Total \\
\hline $1974-75$ to & 383 & 364 & 19 & 415 & 16 & 431 \\
$1997-98$ (24 years) & & $(95.03 \%)$ & $(4.97 \%)$ & $(96.29 \%)$ & $(3.71 \%)$ & \\
\hline
\end{tabular}


Table 1. Wildlife offences committed by different castes, communities, tribes etc. in eastern Rajasthan

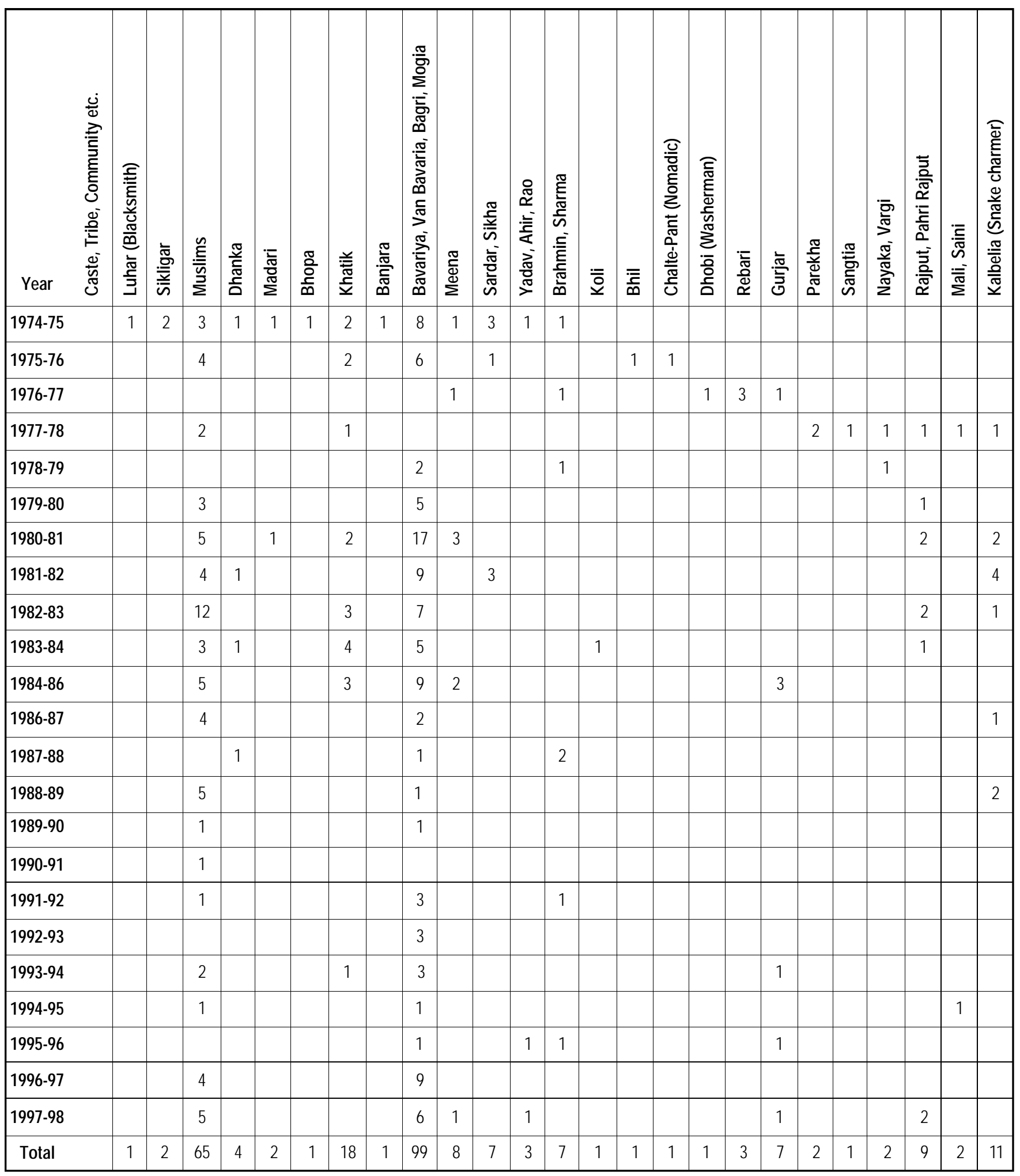


Table 1 (continued). Wildlife offences committed by different castes, communities, tribes etc. in eastern Rajasthan

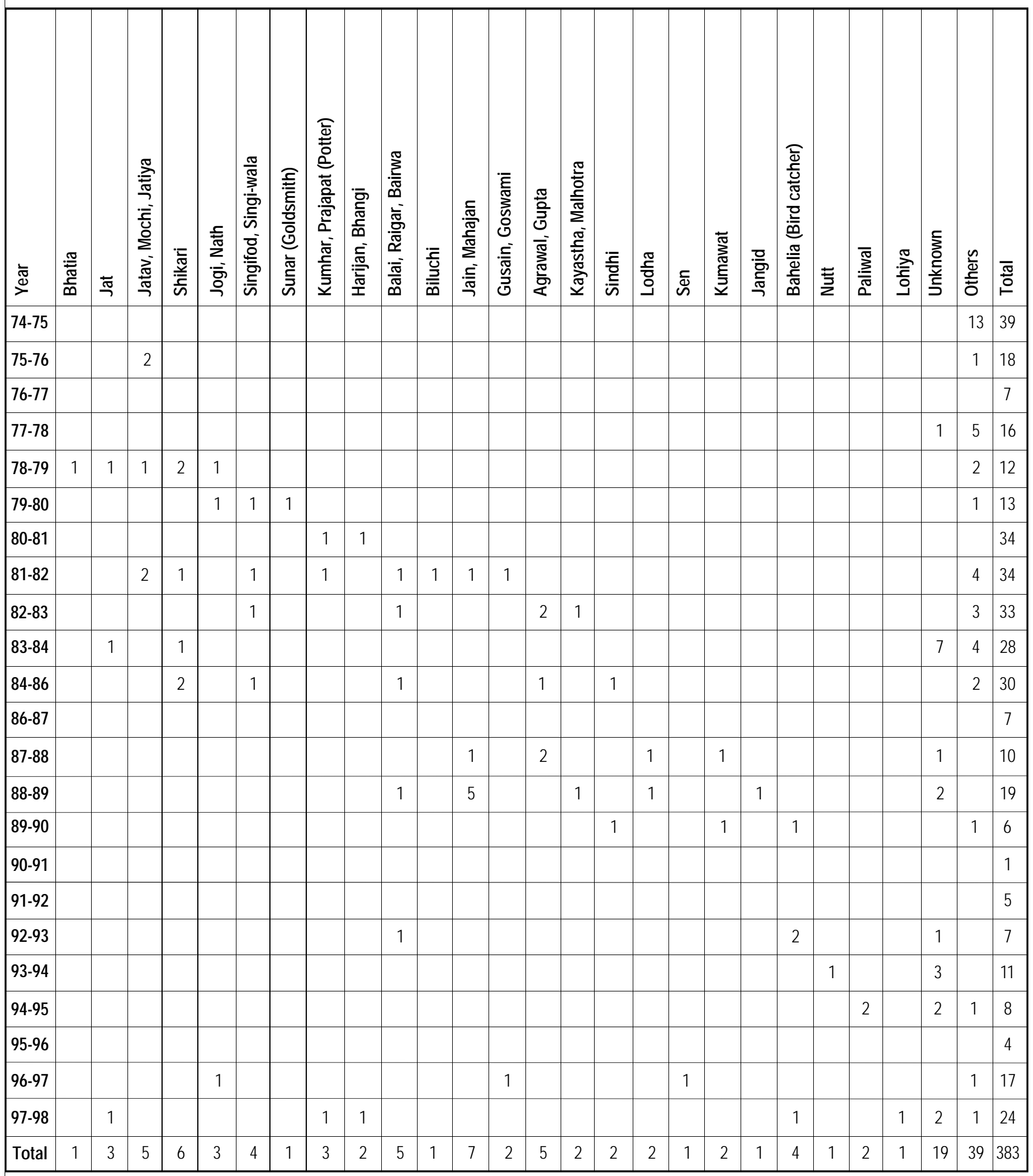


Table 3. Target animals and nature of offence.

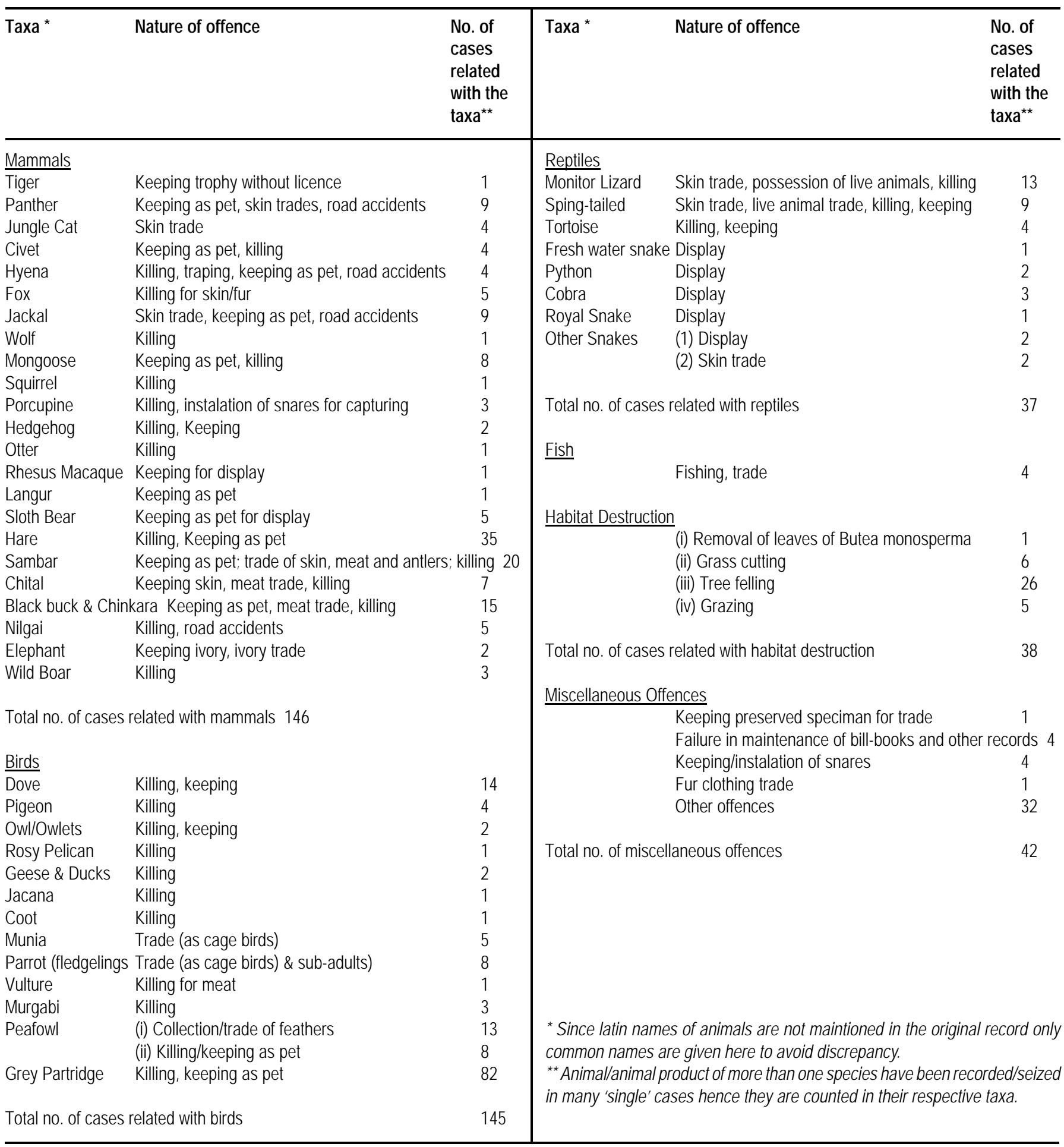


of cats (and other mammals) were recovered from them in surprise raids.

Nilgai is gradually becoming a serious crop pest since top predators have been lost from the vast tracts of Rajasthan (Rajpurohit, 1988). Due to this reason, despite its high religious status in society, Nilgais are sometimes killed for crop protection and occasionally also for meat.

A large number of Muslims and Rajputs are tradionally meat loving and shikar is considered 'sport' by many of them. Hence a higher record of registered cases is to their credit. Unfortunately, due to degradation in religious and ethical values even Jains, Brahmins and other known vegetarian castes are also now indulging in wildlife offences.

Tribals and traditional communities use hunting dogs and traditional weapons like arrows, nets, snare etc. in hunting operation but well off people use modern equipments like fast moving vehicles, guns, rifles, etc. (Sharma, 1998). Table 1 reveals that a wide spectrum of caste, communities etc. are involving in wildlife offences which is an indication of overall degradation of our centuries old religious and ethical values. We can hope that women and Bisnois, who still shy away from wildlife offences, can guide our society to protect wildlife of Rajasthan and India.
By launching an awareness campaign and intensive and extensive patrolling in rural, tribal and urban areas we can conserve our wild-heritage in situ. By overall socio-economic upliftment of poor people of rural areas specially in and around protected areas we can keep away a large section of our society from wildlife offences.

\section{Acknowledgements}

SKS is grateful to Sh. U.M. Sahai CF (WL) and Sh. M.R. Punia for providing facilities. Thanks are also due to Dr. A.L. Bhatia and Miss Kamni Gupta for going through the manuscript.

\section{References}

Deoras, P.J. (1981). Snakes of India (NBTI).

Doshi, S.L. and N.N. Vyas (1992). Tribal Rajasthan: Sunshine on the Aravalli. Himanshu Publications, Udaipur.

Rajpurohit, L.S. (1988). Nilgai, Boselphus tragocamelus, a serious crop pest between Jodhpur and Osian (Rajasthan). Cheetal 29(2): 1013.

Sankhala, K. and V.D. Sharma (1984). Vanishing cats of Rajasthan. Cheetal 26(1). 5-23.

Sharma, S.K. (1998). Ethnozoology. Himanshu Publications, Udaipur. Singh, V. and R.P. Pandey (1998). Ethnobotany of Rajasthan, India Scientific Publishers, Jodhpur. 